\title{
An Optimal Design of LLC Resonant Converter using FireFly Algorithm based Parameter Optimization Approach
}

\author{
Sarath K S \\ Hindustan University, Padur, Chennai \\ sarathksks14@gmail.com
}

\author{
Dr S Sekar \\ Department of EEE \\ Hindustan University, Padur, Chennai
}

\begin{abstract}
The development of power conversion technology is in constant demand due to high power efficiency and high power density. In the resonant converter, huge resonant converter topologies are available and among them, LLC converter is the most attractive one as it is capable of operating in the wide variation range of input voltage and load conditions. Apart from these advantages, LLC Resonant Converter (LLC-RC) suffers from drawbacks like power loss and voltage fluctuations. Thus, this paper intends to develop novel LLC-RC designs on the basis of the Parameter Optimization (PO) algorithm. The proposed model overcomes the major shortcoming by employing a non-conceptual model on the basis of the simulated outcome. The intelligent model is constructed under the start-up conditions with the literary outcomes achieved from the resonant current. As a novelty, the time constant of the resonant converter is optimized by Firefly algorithm (FF). The time constant is optimized on the basis of the objective model, which was obtained from the function of start-up time. The start-up time was diminished and the response speed of the output voltage was increased. Finally, the proposed Firefly algorithm based Parameter Optimization (FF-PO) model was compared with the existing models like Whale Optimization Algorithm based Parameter Optimization (WOA-PO), IAPO, Ant Bee Colony-PO (ABC-PO), Particle Swarm OptimizationPO (PSO-PO) and Grey Wolf Optimization (GWO-PO) on the basis of error and steady-state response.
\end{abstract}

Keywords: LLC resonant converter; Output voltage; peak value; Parameter optimization; RMSE; Firefly algorithm based Parameter Optimization (FF-PO) model.

\section{Introduction}

In recent decades, the usage of electricity becomes a rapidly increasing demand for present power supply industry owing to the rise in the requirements in distributed power supply systems [6] [7]. The process of power conversion is to analyze and supply electricity, further, the power converters are required universally to fulfill the electric power demands. Generally, the power conversion is defined as a significant connection among the supplied power source to the consumer electronic devices/energy transmission/storage products. resonant DC/DC converter is a group of converters with L-C resonant tank working as the main role in power conversion technology [8]. Moreover, the basic ideas behind the construction of resonant converters are the circulating energy available in the L-C resonant circuit is controllable through modifying the operating frequency. Thus, the converter is able to control the input power to the required output voltage. Typically, the resonant converters comprised of three basic parts such as rectifier, switch network, and resonant tank. Usually, the resonant tank performs as a frequency selector for an inverter, while in a converter, the sinusoidal waveform purity is not considered as a rectifier and the output low-pass filter can transform the DC from AC. Further, the different resonant properties of the L-C tank decide the various functionalities of the resonant converters [9] [10]. Moreover, the high fluctuations in the resonance intensify the current distributed to the resonant tank that intensifies the conduction losses as well as balance the benefits of short switching losses [11] [12].

Generally, resonant DC/DC converter is a group of converters with L-C resonant tank working as the main role in power conversion technology [13] [15]. Moreover, the basic ideas behind the construction of resonant converters are the circulating energy available in the L-C resonant circuit is controllable through modifying the operating frequency. In L-C resonant tank structure, it has different types which are the L-C resonant tanks [14] [17]. The Series Resonant Converter (SRC) has the resonant inductor and capacitor in series. Further, the resonant tank is connected serially with the output load resistance as well as the resonant tank impedance $\mathrm{Z}$ performs as a function to the switching frequency [16] [18]. 
The major drawback of SRC is high switching loss in MOSFET converters [19] [20]. The Parallel Resonant Converter (PRC) topology ahs the two resonant components (resonant inductor and Capacitor) in parallel. Here, the peak gain is achieved in the lower frequency. The major drawback of PRC is high conduction loss as well as poor efficiency for light load condition. So, with the intention of overriding these drawbacks, the LCC Resonant Converter (Series-Parallel Resonance Converter) is the combination of SRC and PRC. The major advantages of LLC Resonant Converter (LLC-RC) are zero load handling capability under light load condition [21] [22].

In an LLC-RC topology under the Frequency Domain Method, the higher harmonics of the square wave voltage were ignored [23] [29]. This model provides no details on the operation current or voltage behavior of the converter. The state-plane analysis for LLC-RC depicts the relation between state variables like the resonant currents and voltages using the state-plane diagram. The major drawback of this model is multiple resonant stages concerning the DC characteristic information [24] [25]. In the Time Domain Method of LLC-RC, the periodic resonant current, as well as the voltage waveforms, are achieved by sorting the operation modes. The power losses are higher in this technique [26] [27] [28]. Hence, there is a necessity to have an optimal design for LLC-RC.

The major contribution of this research work is to design a novel LLC-RC converter by optimizing the output voltage and resonant inductor current in order to diminish the error. The proposed FF-PO model is compared with the state-of-art models like IA-PO, ABC-PO, PSO-PO, WOA-PO, and GWO-PO in terms of RMSE and steady-state response.

The rest of the paper is organized as: Section 2 provides a compact review on the related works done in LLC-RC design. Section 3 portrays LLC resonant converter model and Section 4 discusses the parameters optimization for the start-up process. The objective of the LLC converter design is depicted in Section 5. The results acquired and their corresponding discussion is provided in Section 6. Section 7 provides a strong conclusion to this research work.

\section{Literature Survey}

\subsection{Related Works}

In 2019, Kwon et al. [1] formulated the no-load control method using full-bridge structure in order to achieve the plasma sputtering process in the LLC resonant converter. Initially, the plasma was generated by operating the plasma sputtering process under a no-load condition. On the basis of the parasitic component, the proposed no-load control method was evaluated in order to exhibit the enhancement in the performance of the proposed model.

In 2018, Singh [2] developed a novel HV resonant DC-DC converter in MPM based transmitters with the objective of powering the powering Traveling Wave Tube (TWT). In order to additional voltage boost, the LLC converter was made to operate under series resonant frequency. The Symmetrical Quadrupler Rectifier (SQR) based high voltage LLC resonant was utilized to solve the issues related to the discontinuous secondary current. In the differential modes of operation, the SQR, as well as the LLC resonant full-bridge inverter, were coupled together to achieve additional voltage gain.

In 2012, Madheswaran et al. [3] proposed Digital Signal Processor (DSP) based fuzzy controller for LLC resonant converter with the intention of estimating the output voltage regulation and $d$ and supply voltage fluctuations. The proposed model was analyzed in terms of both closed-loop and open-loop conditions using state-space model. In the proposed model, the output voltage was regulated by the fuzzy controller by means of varying the supply voltage and load disturbance.

In 2019, Hua et al. [4] introduced a Dual-Bridge (DB) LLC resonant converter for dc/dc conversion on the basis of the switch integration technique for a wide range of low input voltage. In the Full-Bridge (FB) LLC and Half-Bridge (HB) LLC, the buck-boost converter was employed in the front stage in order to achieve greater input voltage. In addition to this, the magnetizing inductance was maximized. Further, at different input voltages, the different phase-shift modulation gains were used by DB LLC resonant converter at different input voltages.

In 2018, Yang et al. [5]projected a novel bidirectional LLC-C resonant converter for an energy storage system with the aid of normalized symmetry resonant tank. For each of the resonant capacitor, two auxiliary switches were employed in order to provide bypass path between the capacitors. The proposed model operated either forward or backward operating mode on the basis of the switching.

\section{LLC Resonant Converter Model}


Among the DC-DC converter like series resonant converter, parallel resonant converter, and seriesparallel resonance converter, the most favorable topology is LLC-RC as it has high power density as well as high effectiveness. Apart from the error in LLC-RC is high and several works are being conducted in for a further reduction in the error and enhancement in performance as well as a control mechanism. The control scheme broadly adopted to secure real-time measurement is the frequency modulation control scheme. The frequency of switching is governed by diminishing the linear pattern or exponential pattern from higher frequency to steady-state frequency by the frequency modulation control scheme. The high frequency and steady-state frequency are represented suing the notation $\mathrm{f}_{\mathrm{HH}}$ and $\mathrm{f}_{\mathrm{ST}}$, respectively. The mathematical formula for frequency is exhibited in Eq. (1). The time and the frequency-time constant are denoted as $t$ and $\tau$, respectively. It is easier to execute the exponential outline with a first-order filter and during switching the frequency conversion is smoother. On the other hand, the trial-and-error technique describing $\tau$ is wearisome [19], owing to the deficiency in the precise investigation of the dynamic method of the converter. The overall architecture of LLC-RC is shown in Fig.1.

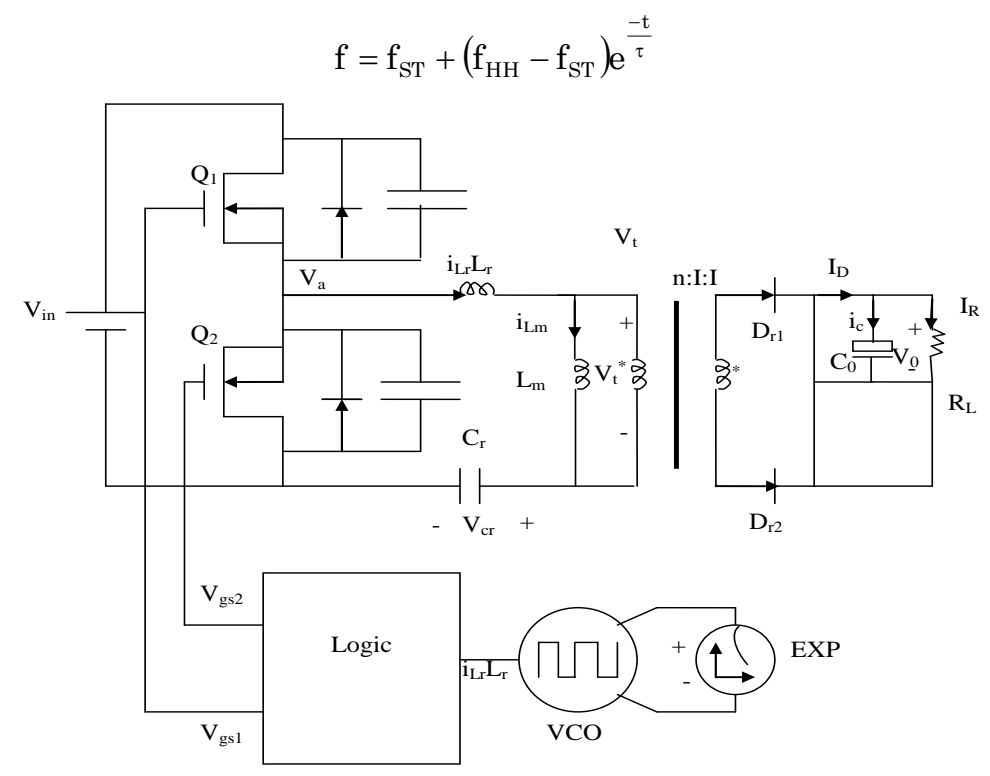

Fig. 1. Overall architecture of the LLC-Resonant converter

\section{Parameter Optimization for the Startup Process}

On the basis of the combined state equations, it is confined that the radius and the center of arc trajectory are closely related to the output voltage. Thus, by measuring the output voltage, the entire state variables involved in the start-up process can be determined.

\subsection{Output Voltage}

The additional current to load is decreased by charging the capacitor with rectifier current. As the required output is achieved from the capacitor during the switching process, the output voltage is considered to be stable and the essential current flows to load. Eq. (2) depicts the mathematical formula for increased output voltage throughout one rectifier duration. The current through the capacitor is represented as $i_{c}$ and the sum of the current from two rectifier diodes, load current and output current are denoted using the notation $\mathrm{i}_{\mathrm{D}}, \mathrm{i}_{\mathrm{R}}$ and $\mathrm{C}_{0}$, respectively. Further, all throughout a rectifier conduction period under steady-state, the output mean value of capacitor current $i_{c}$, as well as the addition of all the magnetic current, $i_{\mathrm{Lm}}$ is symmetrical and equal to zero. Thus, Eq. (2) gets transformed as per Eq. (3). In the rectifier conducting period, the value of the Eq. (4) and Eq. (5) varies from t1 to t3. The resonant capacitor voltage and the resonant capacitor is $\mathrm{V}_{\mathrm{C}_{\mathrm{r}}}$ and $\mathrm{C}_{\mathrm{r}}$, respectively. The critical load resistor is denoted using the notation $\mathrm{R}_{\mathrm{L}}$. In addition, the resonant inductor current, resonant impedance and the switching period is represented as $\mathrm{i}_{\mathrm{Lr}}, \mathrm{Z}_{0}$ and $\mathrm{T}_{\mathrm{s}}$, respectively. On the basis of these parameters, Eq. (6) and Eq. (7) are formulated. The primary phases at time duration $t_{1}$ and $t_{2}$ of arc $\left(x_{1}, 0\right)$ and $\left(x_{2}, 0\right)$ are denoted as $\phi_{1}$ and $\phi_{2}$, respectively. The natural frequency is denoted as $\omega_{0}$ and its corresponding 
mathematical formula is shown in Eq. (8). As per Eq. (9), the current in the inductor is balanced and here the notation for exciting current is $\mathrm{I}_{\mathrm{Lm}}$.

$$
\begin{aligned}
& \Delta \mathrm{V}_{0}=\frac{1}{\mathrm{C}_{0}} \int_{0}^{\frac{\mathrm{T}_{\mathrm{s}}}{2}} \mathrm{i}_{\mathrm{c}} \mathrm{dt}=\frac{1}{\mathrm{C}_{0}} \int_{0}^{\frac{\mathrm{T}_{\mathrm{s}}}{2}}\left(\mathrm{i}_{\mathrm{D}}-\mathrm{i}_{\mathrm{R}}\right) \mathrm{dt} \\
& \mathrm{n} \int_{0}^{\frac{\mathrm{T}_{\mathrm{s}}}{2}} \mathrm{i}_{\mathrm{Lr}} \mathrm{dt} \frac{\mathrm{V}_{0} \mathrm{~T}_{\mathrm{s}}}{2 \mathrm{R}_{\mathrm{L}}}=0 \\
& \int_{0}^{\frac{T_{s}}{2}} \mathrm{i}_{\mathrm{Lr}} \mathrm{dt}=\int_{0}^{\frac{\mathrm{T}_{\mathrm{s}}}{2}} \mathrm{C}_{\mathrm{r}} \frac{\mathrm{dv}_{\mathrm{C}_{\mathrm{r}}} \mathrm{dt}}{\mathrm{dt}}=\mathrm{C}_{\mathrm{r}}\left(\mathrm{V}_{\mathrm{C}_{\mathrm{r} 3}}-\mathrm{V}_{\mathrm{C}_{\mathrm{r}}}\right) \\
& \Delta \mathrm{V}_{0}=\frac{\mathrm{nC}_{\mathrm{r}}\left(\mathrm{V}_{\mathrm{Cr} 3}-\mathrm{V}_{\mathrm{Crl}}\right)}{\mathrm{C}_{0}}-\frac{\mathrm{V}_{0} \mathrm{~T}_{\mathrm{s}}}{2 \mathrm{R}_{\mathrm{L}} \mathrm{C}_{0}} \\
& \left\{\begin{array}{l}
i_{\text {Lrr1 }}=\left.I_{\text {Lrp1 }} \sin \left(\omega_{0} t+\varphi_{1}\right)\right|_{\text {model }} \\
i_{\text {Lr } 2}=\left.I_{\text {Lrp } 2} \sin \left(\omega_{0} t+\varphi_{2}\right)\right|_{\text {mode } 2}
\end{array}\right. \\
& \mathrm{I}_{\mathrm{Lrp1}}=\sqrt{\frac{\left(\mathrm{V}_{\mathrm{Cr} 1}-\mathrm{x}_{1}\right)^{2}}{\mathrm{Z}_{0}^{2}+\left(-\mathrm{I}_{\mathrm{Lm}}\right)^{2}}} \\
& \left\{\mathrm{I}_{\mathrm{Lrp} 2}=\sqrt{\frac{\left(\mathrm{V}_{\mathrm{Cr} 2}-\mathrm{x}_{2}\right)^{2}}{\mathrm{Z}_{0}^{2}+\left(-\mathrm{I}_{\mathrm{Lr}}\right)^{2}}}\right. \\
& \mathrm{V}_{\mathrm{Cr} 2}=\mathrm{I}_{\mathrm{Lrp1}} \mathrm{Z}_{0} \cos \left(\omega_{0} \mathrm{t}_{12}+\varphi_{1}\right)+\mathrm{x}_{1} \\
& \left(\omega_{0}=\frac{1}{\sqrt{\mathrm{L}_{\mathrm{r}} \mathrm{C}_{\mathrm{r}}}}\right) \\
& \left\{\begin{array}{l}
\mathrm{I}_{\mathrm{Lrp1}} \sin \varphi_{1}=-\mathrm{I}_{\mathrm{Lm}} \\
\mathrm{I}_{\mathrm{Lr} 2}=\mathrm{I}_{\text {Lrp1 }} \sin \left(\omega_{0} \mathrm{t}_{12}+\varphi_{1}\right)=\mathrm{I}_{\text {Lrp2 }} \sin \varphi_{2} \\
\mathrm{I}_{\mathrm{Lrp1}} \sin \left(\omega_{0} \mathrm{t}_{23}+\varphi_{2}\right)=\mathrm{I}_{\mathrm{Lm}}
\end{array}\right.
\end{aligned}
$$

In between the time interval $t_{01}$ and $t_{02}$, the time is equal to half of the switching period $\mathrm{T}_{\mathrm{s}}$. The mathematical formula for this case is shown in Eq. (10). The freewheeling period of the rectifier diode is represented using the notation $t_{01}$ and it is equal to $t_{23-\text { last }}$, which is the freewheeling period of the previous mode. These help in evaluating the entire variables required for switching and further the term $\mathrm{V}_{\mathrm{Cr} 3}$ is evaluated as $\Delta \mathrm{V}_{0}$ and the mathematical formula for $\mathrm{V}_{\mathrm{Cr} 3}$ is shown in Eq. (11). In the iteration method, the state variables are measured by fixing $\mathrm{V}_{0}=\mathrm{V}_{\mathrm{Cr}}=\mathrm{I}_{\mathrm{Ir} 1}=\mathrm{I}_{\mathrm{Im}}=\mathrm{t}_{01}=0$ and in mode 1 or 3 , the values of $\mathrm{L}_{\mathrm{rpl}}, \phi_{1}$ and $\mathrm{t}_{12}, \mathrm{~V}_{\mathrm{Cr} 2}$ are computed. In mode 2 or 4 , the values of $\mathrm{L}_{\mathrm{rp} 2}, \phi_{2}$ and $\mathrm{t}_{23}, \mathrm{~V}_{\mathrm{Cr} 3}$ are computed. Then, the value of $\Delta \mathrm{V}_{0}, \mathrm{~V}_{0}, \mathrm{I}_{\mathrm{Lm}}$ is computed and once if the steady-state is reached, the obtained values are the state variables and in case of not reaching the steady-state, the value of $t_{01}=t_{23}$ and $\mathrm{V}_{\mathrm{Cr} 1}=\mathrm{V}_{\mathrm{Cr} 3}$ are assumed and the process is repeated.

$$
\begin{aligned}
& \mathrm{t}_{01}+\mathrm{t}_{02}=\frac{\mathrm{T}_{\mathrm{s}}}{2} \\
& \mathrm{~V}_{\mathrm{Cr} 3}=\mathrm{I}_{\mathrm{Lrp} 2} \mathrm{Z}_{0} \cos \left(\omega_{0} \mathrm{t}_{23}+\varphi_{2}\right)+\mathrm{x}_{2}
\end{aligned}
$$

\subsection{Peak Value of Resonant Current}

At lower switching frequency, the resonant current has reached the peak value and it resembles the amplitude of resonant current and when the frequency of switching is greater at the final moment. When the switching is greater at the final moment value and it is equivalent to the resonant current value of mode 1 and mode 3 . The output voltage at the starting instant is equal to zero and hence the value of $\mathrm{x}_{1}=\mathrm{x}_{4}=\mathrm{V}_{\mathrm{in}}, \mathrm{x}_{2}=\mathrm{x}_{3}=0$. Here, mode 2 and mode 4 are lessened. Eq. (12) depicts the circular trajectory in radian throughout the entire mode of operation. The term $\mathrm{i}_{\mathrm{Lr} 1}, \mathrm{i}_{\mathrm{Lr} 2}, \mathrm{i}_{\mathrm{Lr} 3}$ tells about the resonant current in each model at the finishing point and the normalized frequency is referred to as $f_{n}$ and it is $f_{n}=f / f_{r}$ 


$$
\alpha_{1}=\omega_{0} \frac{T_{s}}{2}=\frac{\pi}{f_{n}}
$$

The mathematical formula for resonant current's peak value in the initial switching duration is exhibited in Eq. (13). The input resistor and the output voltage is denoted using the term $R_{1}$ and $V_{\text {in }}$, respectively. In Eq. (14) and Eq. (15), $\mathrm{i}_{\mathrm{Ir} 1}<\frac{\mathrm{R}_{1}}{\mathrm{Z}_{0}}<\mathrm{i}_{\mathrm{Lr} 3}<\mathrm{i}_{\mathrm{Lr} 2}<\frac{\mathrm{R}_{2}}{\mathrm{Z}_{0}}$ and the vertex angle is denoted as $\theta_{2}$.

$$
\begin{aligned}
& \mathrm{I}_{\mathrm{Lrm}}=\mathrm{i}_{\mathrm{Lr} 1}=\frac{\mathrm{R}_{1}}{\mathrm{Z}_{0}} \sin \left(\frac{\omega_{0} \mathrm{~T}_{\mathrm{s}}}{2}\right)=\frac{\mathrm{V}_{\text {in }}}{\mathrm{Z}_{0}} \sin \left(\frac{\pi}{\mathrm{f}_{\mathrm{n}}}\right)\left(\mathrm{f}_{\mathrm{n}}>2\right) \\
& \mathrm{R}_{2}=2 \mathrm{R}_{1} \sin \left(\frac{\alpha_{1}}{2}\right)=2 \mathrm{~V}_{\text {in }} \sin \frac{\omega_{0} \mathrm{~T}_{\mathrm{s}}}{4}=2 \mathrm{~V}_{\text {in }} \sin \left(\frac{\pi}{2 \mathrm{f}_{\mathrm{n}}}\right) \\
& \mathrm{I}_{\mathrm{Lrm}}=\mathrm{i}_{\mathrm{Lr} 2}=\frac{\mathrm{R}_{2}}{\mathrm{Z}_{0}} \sin \left(\alpha_{1}-\theta_{2}\right)=\frac{\mathrm{R}_{2}}{\mathrm{Z}_{0}} \sin \left(\alpha_{1}-\left(\frac{\pi}{2}-\frac{\alpha_{1}}{2}\right)\right) \\
& \mathrm{I}_{\mathrm{Lrm}}=\frac{\mathrm{V}_{\text {in }}}{\mathrm{Z}_{0}} \sin \left(\frac{\pi}{\mathrm{f}_{\mathrm{n}}}\right)-\sin \left(\frac{2 \pi}{\mathrm{f}_{\mathrm{n}}}\right) \quad\left(1.5<\mathrm{f}_{\mathrm{n}} \leq 2\right)
\end{aligned}
$$

\section{Objective Function of LLC Converter Design}

\subsection{Objective Function and Solution Encoding}

The major objective of this research is to diminish the error function $\mathrm{G}$, which is the total error $e^{*}$ between the error measurement $e_{1}$ and error measurement $e_{2}$. The error measurement $e_{1}$ is the error between the output voltage $V_{0}$ and the desired output voltage $V_{0}^{D}$. The error measurement $e_{2}$ is the difference between the peak value of resonant current $I_{L r m}$ and the desired peak value of resonant current $\mathrm{I}_{\mathrm{Lrm}}^{\mathrm{D}}$. The mathematical formula for error measurement $\mathrm{e}_{1}$ and the error measurement $\mathrm{e}_{2}$ is shown in Eq. (21) and Eq. (22), correspondingly. The mathematical formula for total error measurement $e^{*}$ is the addition of the errors $\mathrm{e}_{1}$ and $\mathrm{e}_{2}$ as per Eq. (19). Further, Eq. (20) depicts the mathematical formula for the error function $G$.

$$
\begin{aligned}
& \mathrm{e}_{1}=\left(\mathrm{V}_{0}^{\mathrm{D}}-\mathrm{V}_{0}\right) \\
& \mathrm{e}_{1}=\left(\mathrm{I}_{\mathrm{Lrm}}^{\mathrm{D}}-\mathrm{I}_{\mathrm{Lrm}}\right) \\
& \mathrm{e}^{*}=\mathrm{e}_{1}+\mathrm{e}_{2} \\
& \mathrm{G}=\operatorname{Min}\left(\mathrm{e}^{*}\right)
\end{aligned}
$$

The solutions $\mathrm{C}_{\mathrm{r},} \mathrm{L}_{\mathrm{r},} \phi$ and $\tau$ are encoded for obtaining the objective function (i.e., attaining minimum $\mathrm{I}_{\mathrm{Lrm}}$ and $\mathrm{V}_{0}$ values). The term $\mathrm{C}_{\mathrm{r},} \mathrm{L}_{\mathrm{r}}$, $\phi$ and $\tau$ depicts the resonant capacitor, resonant inductor, angle of the initial point and frequency time constant, respectively. The lower limit of $\mathrm{C}_{\mathrm{r}}$ is $\mathrm{e}^{-6}$ and the upper limits is $100 \mathrm{e}^{-6}$. The lower limit of $\mathrm{L}_{\mathrm{r}}$ is $\mathrm{e}^{-9}$ and the upper limit is $5 \mathrm{e}^{-9}$. The upper limit and the lower limit of $\phi$ is 1 and $\mathrm{e}^{3}$, respectively and the lower limit and upper limits of $\tau$ are 1 and 100 respectively. The diagrammatic representation of the solution encoding is shown in Fig. 2.

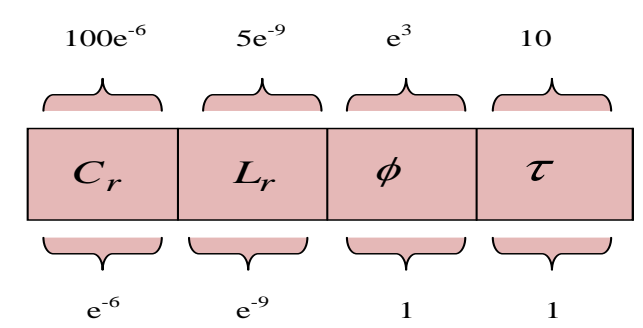

Fig. 2. Solution encoding process 


\subsection{Standard Firefly Algorithm}

As mentioned before, the solutions such as $\mathrm{C}_{\mathrm{r},} \mathrm{L}_{\mathrm{r},} \phi$ and $\tau$ are optimized using $\mathrm{FF}$ algorithm [35] and [36]. This algorithm was introduced in the year 2008 by Xin-She. Three major assumptions of FF are (a) (a) all FF are unisex (b) Attractiveness $\rho$ of $\mathrm{FF}$ a brightness and Attractiveness of $\mathrm{FF}$ a $1 /$ distance between fireflies. (c) The brightness of FF is defined in terms of the objective function. The attractiveness of $\mathrm{FF}$ is denoted as $\rho$ is directly proportional to distance $x$. The mathematical formula for attractiveness between two EE is shown in Eq. (17), in which the maximum attractiveness (light absorption coefficient) is denoted as $\rho_{0}$. In addition, $K_{g}$ is the position of $g^{\text {th }} \mathrm{FF}$ and $K_{h}$ is the position of $h^{\text {th }} F F$. Then, Eq. (18) depicts the mathematical formula for the distance between two FF, in which the notation $b$ is the count of the dimensions. Eq. (23) depicts the movement of FF and on the basis of the distance between FF; the value of $\mathrm{M}_{\mathrm{h}}$ (light intensity) is measured. The initial position of FF is denoted as per Eq. (24), in which the first term tells about the current position of $\mathrm{FF}$, the second term portrays the attractiveness of $\mathrm{FF}$ and the last term depicts the random movement of FF. The represents the original light intensity is depicted using the term $\mathrm{M}_{0}$. The pseudo-code for conventional FF is shown in Algorithm 1.

$$
\begin{aligned}
& \mathrm{M}=\mathrm{M}_{0} \mathrm{e}^{-\gamma \mathrm{x}} \\
& \rho(\mathrm{x})=\rho_{0} \mathrm{e}^{-\gamma \mathrm{x}}, \mathrm{v} \geq 1 \\
& \mathrm{x}_{\mathrm{gh}}=\left\|\mathrm{K}_{\mathrm{g}}-\mathrm{K}_{\mathrm{h}}\right\|=\sqrt{\sum_{\mathrm{w}=1}^{\mathrm{b}}\left(\mathrm{K}_{\mathrm{g}, \mathrm{w}}-\mathrm{K}_{\mathrm{h}, \mathrm{u}}\right)^{2}} \\
& \mathrm{~K}_{\text {best }}=\mathrm{K}_{\mathrm{g}}+\rho_{0}{ }^{-\gamma \mathrm{x}_{\mathrm{gh}}^{2}}\left(\mathrm{~K}_{\mathrm{h}}-\mathrm{K}_{\mathrm{g}}\right)+\omega\left(\text { rand }-\frac{1}{2}\right)
\end{aligned}
$$

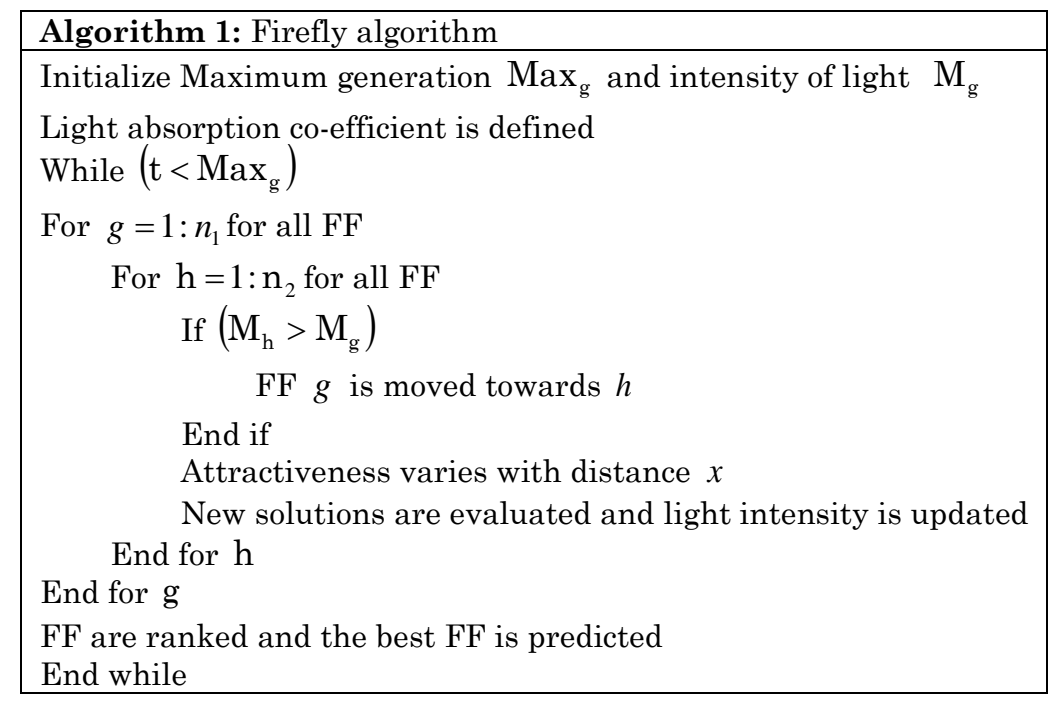

Thus by adopting FF technique, the parameters such as $\mathrm{I}_{\mathrm{Lrm}}$ and $\mathrm{V}_{0}$ can be minimized by optimizing the relevant parameters.

\section{Results and Discussions}

\subsection{Simulation Procedure}

The proposed LCR-RC model on the basis of the FF-PO algorithm was simulated in MATLAB, and the optimal results were obtained. In this experiment, the value of $\mathrm{I}_{\mathrm{Irm}}$ and $\mathrm{V}_{0}$ are optimized and the steadystate response is recorded. It was analyzed for three different experiments by fixing the set points of $\left(\mathrm{I}_{\mathrm{Irm}}, \mathrm{V}_{0}\right)$ at $(15,23),(5,20)$ and $(10,25)$, respectively for experiment 1 , experiment 2 and experiment 3 , respectively. The proposed FF-PO model was compared with other conventional models like IA-PO [35], ABC-PO [31], PSO-PO [32], WOA-PO [33] and GWO-PO [34]. 


\subsection{Error Analysis}

RMSE of the proposed FF-PO model for LLC-RC for three set points namely, $(15,23),(5,20)$ and $(10,25)$ for $I_{\text {Irm }}$ and $V_{0}$ is shown in Fig. 3(a) and Fig. 3(b), respectively. Fig. 3(a) depicts the RMSE values obtained by varying $I_{\mathrm{Irm}}$ for three set points namely, $(15$, and 23$),(5,20)$ and $(10,25)$. For the first experiment (Experiment -1), the value of FF-PO is $92 \%$ and $51 \%$ better than IA-PO and ABC-PO techniques, respectively. In the second experiment (Experiment-2), the proposed FF-PO model in terms of RMSE for varying $\mathrm{I}_{\mathrm{Lrm}}$ is $29.8 \%$ and $14 \%$ better than the traditional PSO-PO and FFPO technique. In Experiment-3, the RMSE of the proposed FF-PO model is $94.7 \%$ superior to IA-PO and $73 \%$ superior to GWO-PO technique. Thus, from this analysis on RMSE values for varying $\mathrm{I}_{\mathrm{Lrm}}$, the proposed FF-PO model exhibits better performance.

Fig. 3(b) illustrates the RMSE values obtained by varying $V_{0}$ for three experiments (Experiments -1, Experiment -2, and Experiment-3) for three set points namely, $(15,23),(5,20)$ and $(10,25)$, respectively. RMSE value of the proposed FF-PO for Experiment- 1 is $59.8 \%$ and $3.8 \%$ better than the state-of-art model like IA-PO and ABC-PO techniques, respectively. In Experiment-2, RMSE value of the proposed FF-PO model is $35.7 \%$ better than PSO-PO and $14.2 \%$ better than GWO-PO, respectively. In Experiment-3, the proposed FF-PO method is $45.8 \%$ superior to IA-PO and $20.6 \%$ superior to GWO-PO techniques. Thus, from this analysis on RMSE values for varying $V_{0}$, the proposed FF-PO model exhibits better performance.

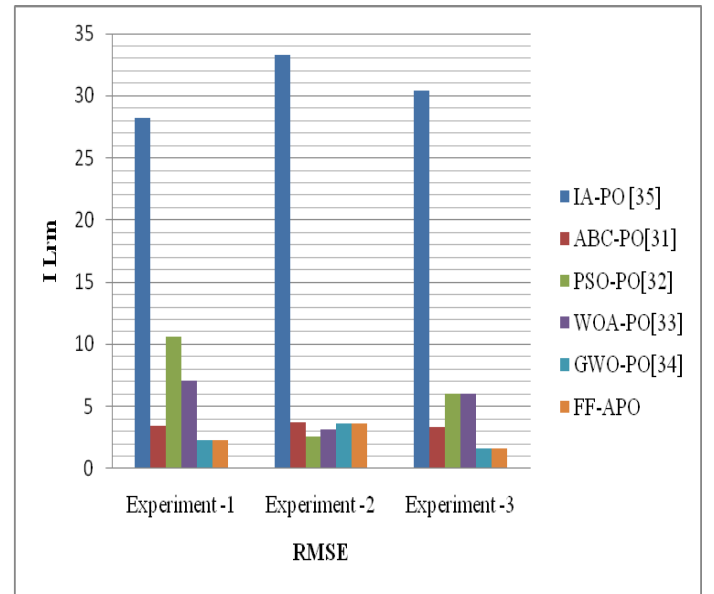

(a)

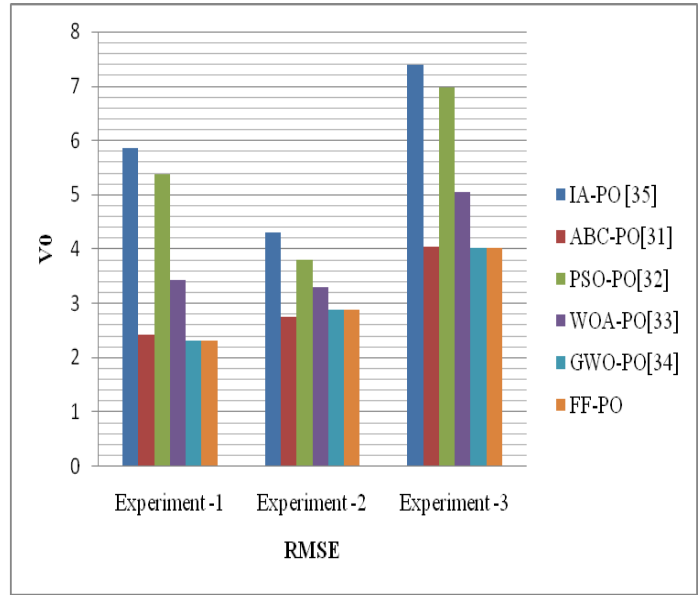

(b)

Fig. 3. Graphical representation of RMSE value obtained by varying (a) $\mathrm{I}_{\mathrm{Lrm}}$ (b) $\mathrm{V}_{0}$

\subsection{Analysis of the Steady-State Response}

The proposed FF-PO model is analysed in terms of , rise time, settling time, settling minimum, settling maximum, overshoot, undershoot, peak and peak time for three different experiments by fixing the set points of $\left(\mathrm{I}_{\mathrm{Irm}}, \mathrm{V}_{0}\right)$ at $(15,23),(5,20)$ and $(10,25)$, respectively. Table 1 depicts the steady-state response $\mathrm{I}_{\mathrm{Lrm}}$ corresponding to Experiment -1. From the analysis, it is clear that the Settling Time is lowest in the proposed model FF-PO and the corresponding value is 8.555574. The setting time of the conventional models like IA-PO, ABC-PO, PSO-PO, WOA-PO, and GWO-PO is 45.98023, 17.779576, 23.71366, 16.371086 and 8.557208, respectively. The minimum Settling time is achieved by FF-PO as 5.002178. Table 2 depicts the corresponding values of $\mathrm{V}_{0}$ for different experiments. The minimum setting level is low in the proposed FF-PO model and it is 10.47603, the other levels are 12.54166, 14.50717, 18.54166, 13.03174, and 12.48852 for IA-PO, ABC-PO, PSO-PO, WOA-PO, and GWO-PO, respectively. The overshoot value of the proposed FF-PO model is 0.107007 and the peak value is 12.9905 . Table 3 show casts the steady-state analysis for $\mathrm{I}_{\mathrm{Lrm}}$ for Experiment-2. The rise time $=0$ for both the proposed as well as the existing model. The lowest Settling Time is 7.77782 and it is achieved in proposed FF-PO. The Settling Minimum has the lowest value as 5.000397 and the setting max value as 22.70768 for the proposed FF-PO model. The Overshoot and the Undershoot value of proposed FF-PO model are 554.1017 and 1.835594, correspondingly. Table 4 exhibits the steady-state $\mathrm{V}_{0}$ analysis for Experiment-2 in which the Settling Time of FF-PO is 13.15255 and it is $54.45 \%, 11.9 \%, 49.48 \%$, and $0.02 \%$ better than IA-PO, ABC-PO, PSO-PO, WOA-PO, and GWO-PO, respectively. Table 5 exhibits the steady-state analysis for 
$\mathrm{I}_{\mathrm{Lrm}}$ Experiment-3, from which the overshoot of the proposed FF-PO model is 47.58612 , which is $88.8 \%$ better than IA-PO, 34.9\% better than ABC-PO, 83.3\% better than WOA-PO and $85.2 \%$ better than GWOPO. Table 6 depicts the steady-state analysis for $\mathrm{V}_{0}$ regarding Experiment-3. Here, the value of Settling Time for the proposed FF-PO model is 8.962245 and it is $47.5 \%, 51.6 \%, 44.3 \%, 32 \%$, and $0.7 \%$ better than existing than IA-PO, ABC-PO, PSO-PO, WOA-PO, and GWO-PO, respectively.

Table 1. Analysis of Steady-state Stability for $\mathrm{I}_{\mathrm{Lrm}}$ for $1^{\text {st }}$ experiment

\begin{tabular}{lllllll}
\hline Methods & IA-PO [35] & ABC-PO [31] & PSO-PO [32] & WOA-PO [33] & GWO-PO [34] & FF-PO \\
Rise time & 0 & 0 & 0 & 0 & 0 & 0 \\
Settling Time & 45.98023 & 7.779576 & 23.71366 & 6.371086 & 8.557208 & 8.555574 \\
Settling Min & 3.902498 & 15.19063 & 3.902498 & 1.506247 & 5.111981 & 5.002178 \\
Settling Max & 59.58278 & 18.57222 & 22.83132 & 74.93567 & 24.59467 & 24.40701 \\
Overshoot & 1426.785 & 20.57158 & 485.0438 & 501.9619 & 63.96446 & 62.73971 \\
Undershoot & 0 & 74.29702 & 0 & 20.42285 & 0 & 0 \\
Peak & 59.58278 & 18.57222 & 22.83132 & 74.93567 & 24.59467 & 24.40701 \\
Peak Time & 45 & 6 & 3 & 3 & 3 & 3 \\
\hline
\end{tabular}

Table 2. Analysis of Steady-state Stability for $\mathrm{V}_{0}$ for $1^{\text {st }}$ experiment

\begin{tabular}{lllllll}
\hline Methods & IA-PO [35] & ABC-PO [31] & PSO-PO [32] & WOA-PO [33] & GWO-PO [34] & FF-PO \\
Rise time & 0 & 0 & 0 & 0 & 0 & 0 \\
Settling Time & 7.09298 & 4.512533 & 6.10274 & 7.12522 & 3.065112 & 2.107312 \\
Settling Min & 12.54166 & 14.50717 & 18.54166 & 13.03174 & 12.48852 & 10.47603 \\
Settling Max & 19.52631 & 13.2531 & 20.52631 & 33.48649 & 22.98853 & 12.9905 \\
Overshoot & 0 & 0.001192 & 0 & 61.10978 & 0.106135 & 0.107007 \\
Undershoot & 0 & 0 & 0 & 0 & 0 & 0 \\
Peak & 10.52631 & 13.2531 & 10.52631 & 23.48649 & 12.98853 & 12.9905 \\
Peak Time & 100 & 12 & 100 & 2 & 6 & 6 \\
\hline
\end{tabular}

Table 3. Analysis of Steady-state Stability for $\mathrm{I}_{\mathrm{Lrm}}$ for $2^{\text {nd }}$ experiment

\begin{tabular}{lllllll}
\hline Methods & IA-PO [35] & ABC-PO [31] & PSO-PO [32] & WOA-PO [33] & GWO-PO [34] & FF-PO \\
\hline Rise time & 0 & 0 & 0 & 0 & 0 & 0 \\
Settling Time & 35.98023 & 8.65921 & 14.78616 & 8.01649 & 9.77991 & 7.77782 \\
Settling Min & 3.902498 & 5.250561 & 4.285375 & 4.997268 & 4.999946 & 5.000397 \\
Settling Max & 49.58278 & 24.28264 & 10.06399 & 16.51892 & 22.70482 & 22.70768 \\
Overshoot & 1426.785 & 552.9328 & 368.1968 & 430.6683 & 554.1035 & 554.1017 \\
Undershoot & 0 & 3.117753 & 0 & 0 & 1.833235 & 1.835594 \\
Peak & 39.58278 & 14.28264 & 8.06399 & 16.51892 & 12.70482 & 12.70768 \\
Peak Time & 45 & 3 & 3 & 3 & 3 & 3 \\
\hline
\end{tabular}

Table 4. Analysis of Steady-state Stability for $\mathrm{V}_{0}$ for $2^{\text {nd }}$ experiment

\begin{tabular}{lllllll}
\hline Methods & IA-PO [35] & ABC-PO [31] & PSO-PO [32] & WOA-PO [33] & GWO-PO [34] & FF-PO \\
\hline Rise time & 0 & 0 & 0 & 0 & 0 & 0 \\
Settling Time & 27.09298 & 11.75384 & 25.88162 & 17.8867 & 13.15562 & 13.15255 \\
Settling Min & 18.54166 & 18.59842 & 19.03922 & 18.89421 & 18.64038 & 18.64128 \\
Settling Max & 20.52631 & 20.17241 & 21.02916 & 20.96248 & 20.17241 & 20.17241 \\
Overshoot & 0 & 0 & 0 & 0 & 0 & 0 \\
Undershoot & 0 & 0 & 0 & 0 & 0 & 0 \\
Peak & 20.52631 & 20.17241 & 21.02916 & 20.96248 & 20.17241 & 20.17241 \\
Peak Time & 100 & 100 & 100 & 100 & 100 & 100 \\
\hline
\end{tabular}

Table 5. Analysis of Steady-state Stability for $\mathrm{I}_{\mathrm{Lrm}}$ for 3 rd experiment

\begin{tabular}{lllllll}
\hline Methods & IA-PO [35] & ABC-PO [31] & PSO-PO [32] & WOA-PO [33] & GWO-PO [34] & FF-PO \\
\hline Rise time & 0 & 0 & 0 & 0 & 0 & 0 \\
Settling Time & 25.98023 & 8.459763 & 13.71366 & 7.482513 & 8.16852 & 6.06433 \\
Settling Min & 3.902498 & 20.13032 & 13.902498 & -9.58209 & 25.007195 & 5.22978 \\
Settling Max & 39.58278 & 17.80458 & $10 . .83132$ & 42.32365 & 6.78018 & 6.77473 \\
Overshoot & 426.785 & 73.1331 & 285.0438 & 323.2078 & 47.80226 & 47.58612 \\
Undershoot & 0 & 0 & 0 & 95.81646 & 0 & 0 \\
Peak & 59.58278 & 37.80458 & 22.83132 & 62.32365 & 16.78018 & 16.77473 \\
Peak Time & 45 & 3 & 3 & 3 & 6 & 6 \\
\hline
\end{tabular}


Table 6. Analysis of Steady-state Stability for $\mathrm{V}_{0}$ for $3^{\text {rd }}$ experiment

\begin{tabular}{lllllll}
\hline Methods & IA-PO [35] & ABC-PO [31] & PSO-PO [32] & WOA-PO [33] & GWO-PO [34] & FF-PO \\
\hline Rise time & 0 & 0 & 0 & 0 & 0 & 0 \\
Settling Time & 17.09298 & 5.911161 & 16.10274 & 13.369537 & 9.029978 & 8.962245 \\
Settling Min & 8.54166 & 10.25554 & 8.54166 & 10.18556 & 10.76239 & 10.7993 \\
Settling Max & 10.52631 & 12.1793 & 10.52631 & 11.8122 & 12.72726 & 12.72052 \\
Overshoot & 0 & $7.29 \mathrm{E}-09$ & 0 & 6.009367 & 0 & 0 \\
Undershoot & 0 & 0 & 0 & 0 & 0 & 0 \\
Peak & 10.52631 & 12.1793 & 10.52631 & 11.8122 & 12.72726 & 12.72052 \\
Peak Time & 100 & 29 & 100 & 2 & 76 & 75 \\
\hline
\end{tabular}

\section{Conclusion}

This paper projected an LLC-RC design model by means of optimizing the parameters like output voltage and resonant inductor current with the help of FF-PO model. The proposed model reduced the error of the system. The modified design in the optimization process was updated using FF-PO model. Finally, the proposed FF-PO model was compared with existing methods like IA-PO, ABC-PO, PSO-PO, WOA$\mathrm{PO}$, and GWO-PO in terms of error and steady-state analysis by varying $\mathrm{I}_{\text {Irm }}$ and $\mathrm{V}_{0}$. The value of Settling Time for the proposed FF-PO model for Experiment- 3 is 8.962245 and it is $47.5 \%, 51.6 \%, 44.3 \%$, $32 \%$, and $0.7 \%$ better than existing than IA-PO, ABC-PO, PSO-PO, WOA-PO, and GWO-PO, respectively.

\section{Compliance with Ethical Standards}

Conflicts of interest: Authors declared that they have no conflict of interest.

Human participants: The conducted research follows the ethical standards and the authors ensured that they have not conducted any studies with human participants or animals.

\section{References}

[1] Min-Jun Kwon,Woo-Cheol Lee,"No-Load Control Method of LLC Resonant Converter for Plasma Sputtering Process Using Full-Bridge Structure",Journal of Electrical Engineering \& Technology,col.14, no.2,pp.pp 795803,March 2019.

[2] Amit Kumar Singh,"A SQR Based High Voltage LLC Resonant DC-DC Converter", Analysis and Design of Power Converter Topology, 2018.

[3] M. Madheswaran,C. Nagarajan,"DSP based fuzzy controller for series parallel resonant converter",Frontiers of Electrical and Electronic Engineering,vol.7, no.4, pp 438-446,December 2012.

[4] Chih-Chiang Hua, Yung-Lin Deng,"A Novel Dual-Bridge LLC Resonant Converter with Wide Range of Low Input Voltage",Energy Procedia,vol.156,pp.361-365,January 2019.

[5] Dongjiang Yang, Bin Duan, Wenlong Ding, Jinqiu Song, Chenghui Zhang,"A bidirectional LLC-C Resonant DCDC Converter Based on Normalized Symmetry Resonant Tank",IFAC-PapersOnLine, vol.15,no.31,pp.685689,2018 .

[6] Hui-pin Lin, Xiao-guang Jin, Liang Xie, Jin Hu and Zheng-yu Lu, "A new variable-mode control strategy for LLC resonant converters operating in a wide input voltage range", vol. 18, no. 3, pp. 410-422, March 2017.

[7] X. Fang et al., "Efficiency-Oriented Optimal Design of the LLC Resonant Converter Based on Peak Gain Placement,"IEEE Transactions on Power Electronics, vol. 28, no. 5, pp. 2285-2296, May 2013.

[8] [8] X. Fang, H. Hu, Z. J. Shen and I. Batarseh, "Operation Mode Analysis and Peak Gain Approximation of the LLC Resonant Converter, "IEEE Transactions on Power Electronics, vol. 27, no. 4, pp. 1985-1995, April 2012.

[9] R. Yu, G. K. Y. Ho, B. M. H. Pong, B. W. K. Ling and J. Lam, "Computer-Aided Design and Optimization of High-Efficiency LLC Series Resonant Converter, "IEEE Transactions on Power Electronics, vol. 27, no. 7, pp. 3243-3256, July 2012.

[10] G. Ivensky, S. Bronshtein and A. Abramovitz, "Approximate Analysis of Resonant LLC DC-DC Converter, "IEEE Transactions on Power Electronics, vol. 26, no. 11, pp. 3274-3284, Nov. 2011.

[11] R. L. Steigerwald, "A comparison of half-bridge resonant converter topologies,"IEEE Transactions on Power Electronics, vol. 3, no. 2, pp. 174-182, Apr 1988.

[12] M. P. Foster, C. R. Gould, A. J. Gilbert, D. A. Stone and C. M. Bingham, "Analysis of CLL Voltage-Output ResonantConverters Using Describing Functions,"IEEE Transactions on Power Electronics, vol. 23, no. 4, pp. 1772-1781, July 2008.

[13] J. F. Lazar and R. Martinelli, "Steady-state analysis of the LLC series resonant converter," APEC 2001. Sixteenth Annual IEEE Applied Power Electronics Conference and Exposition (Cat. No.01CH37181), vol.2, pp. 728-735, 2001. 
[14] P. Kowstubha, K. Krishnaveni and K. Ramesh Reddy, "Performance analysis of pulse analog control schemes for LLC resonant DC/DC converters suitable in portable applications", Journal of Electrical Systems and Information Technology, vol. 3, no. 3, pp. 454-470, December 2016.

[15] G. De Falco, M. Riccio, G. Breglio and A. Irace, "Thermal-aware design and fault analysis of a DC/DC parallel resonant converter", Microelectronics Reliability, vol. 54, no. 9-10, pp. 1833-1838, 2014.

[16] F. Giri, O. El Maguiri, H. El Fadil and F.Z. Chaoui, "Nonlinear adaptive output feedback control of series resonant DC-DC converters", Control Engineering Practice, vol. 19,no. 10, pp. 1238-1251, October 2011.

[17] Chengchan Kaewanuchit, "Small - Signal Model of Series - Parallel Resonant DC-DC Converter with Capacitive Output Filter", Procedia Engineering, vol. 8, pp. 42-46, 2011.

[18] U. Kundu; P. Sensarma, "A Unified Approach for Automatic Resonant Frequency Tracking in LLC DC-DC Converter,"IEEE Transactions on Industrial Electronics, vol.PP, no.99, pp.1-1, 2017.

[19] H. Wang, Y. Chen, Y. F. Liu, J. Afsharian and Z. Yang, "A Passive Current Sharing Method With Common Inductor Multiphase LLC Resonant Converter,"IEEE Transactions on Power Electronics, vol. 32, no. 9, pp. 69947010, Sept. 2017.

[20] J. H. Jung, H. S. Kim, M. H. Ryu and J. W. Baek, "Design Methodology of Bidirectional CLLC Resonant Converter for High-Frequency Isolation of DC Distribution Systems,"IEEE Transactions on Power Electronics, vol. 28, no. 4, pp. 1741-1755, April 2013.

[21] W. Chen, P. Rong and Z. Lu, "Snubberless Bidirectional DC-DC Converter With New CLLC Resonant Tank Featuring Minimized Switching Loss,"IEEE Transactions on Industrial Electronics, vol. 57, no. 9, pp. 3075-3086, Sept. 2010.

[22] J. W. Kim, J. K. Han and J. S. Lai, "APWM adapted half-bridge LLC converter with voltage doubler rectifier for improving light load efficiency,"Electronics Letters, vol. 53, no. 5, pp. 339-341, 322017.

[23] W. Sun, H. Wu, H. Hu and Y. Xing, "Modified LLC resonant converter with secondary paralleled bidirectional switch for applications with hold-up time requirement,"IET Power Electronics, vol. 10, no. 3, pp. 398-404, 2017.

[24] A. K. Singh, P. Das and S. K. Panda, "Analysis and Design of SQR-Based High-Voltage LLC Resonant DC-DC Converter,"IEEE Transactions on Power Electronics, vol. 32, no. 6, pp. 4466-4481, June 2017.

[25] H. Wang, Y. Chen, P. Fang, Y. F. Liu, J. Afsharian and Z. Yang, "An LLC Converter Family With Auxiliary Switch for Hold-Up Mode Operation,"IEEE Transactions on Power Electronics, vol. 32, no. 6, pp. 4291-4306, June 2017.

[26] J. W. Kim, J. P. Moon and G. W. Moon, "Duty-Ratio-Control-Aided LLC Converter for Current Balancing of TwoChannel LED Driver,"IEEE Transactions on Industrial Electronics, vol. 64, no. 2, pp. 1178-1184, Feb. 2017.

[27] T. Mishima, H. Mizutani and M. Nakaoka, "A Sensitivity-Improved PFM LLC Resonant Full-Bridge DC-DC Converter With LC Antiresonant Circuitry,"IEEE Transactions on Power Electronics, vol. 32, no. 1, pp. 310-324, Jan. 2017.

[28] J. B. Lee, J. K. Kim, J. I. Baek, J. H. Kim and G. W. Moon, "Resonant Capacitor On/Off Control of Half-Bridge LLC Converter for High-Efficiency Server Power Supply,"IEEE Transactions on Industrial Electronics, vol. 63, no. 9, pp. 5410-5415, Sept. 2016.

[29] S. Zong, H. Luo, W. Li, Y. Deng and X. He, "Asymmetrical Duty Cycle-Controlled LLC Resonant Converter With Equivalent Switching Frequency Doubler,"IEEE Transactions on Power Electronics, vol. 31, no. 7, pp. 49634973, July 2016.

[30] F. Duan, M. Xu, X. Yang and Y. Yao, "Canonical Model and Design Methodology for LLC DC/DC Converter With Constant Current Operation Capability Under Shorted Load,"IEEE Transactions on Power Electronics, vol. 31, no. 10, pp. 6870-6883, Oct. 2016.

[31] P. Shunmugapriya, S. Kanmani, "A hybrid algorithm using ant and bee colony optimization for feature selection and classification (AC-ABC Hybrid)", Swarm and Evolutionary Computation, vol. 36, pp. 27-36, October 2017.

[32] Nandar Lynn, Ponnuthurai Nagaratnam Suganthan, "Ensemble particle swarm optimizer", Applied Soft Computing, vol. 55, pp. 533-548, June 2017.

[33] Seyedali Mirjalili, Andrew Lewis, "The Whale Optimization Algorithm", Advances in Engineering Software, vol. 95, pp. 51-67, May 2016.

[34] Abdul Kayom Md Khairuzzaman, Saurabh Chaudhury, "Multilevel thresholding using grey wolf optimizer for image segmentation”, Expert Systems with Applications, vol. 86, pp. 64-76, 15 November 2017.

[35] R. Zheng, B. Liu and S. Duan, "Analysis and Parameter Optimization of Start-Up Process for LLC Resonant Converter, "IEEE Transactions on Power Electronics, vol. 30, no. 12, pp. 7113-7122, Dec. 2015.

[36] G Singh, VK Jain, A Singh, "Adaptive network architecture and firefly algorithm for biogas heating model aided by photovoltaic thermal greenhouse system",Energy \& Environment, vol. 29 (7), pp.1073-1097, 2018. 